This is the accepted version of the following article:

Microporous Materials 6 (1996) 213-229, which has been published in final form at http://www.sciencedirect.com/science/article/pii/0927651396000028

\title{
Properties of Organic Cations That Lead to the Structure-Direction of High-Silica Molecular Sieves
}

Yoshihiro Kubota ${ }^{\mathrm{a}}$, Matthew M. Helmkamp ${ }^{\mathrm{a}}$, Stacey I. Zones ${ }^{\mathrm{b}}$, and Mark E. Davis ${ }^{\mathrm{a}, *}$

${ }^{a}$ Division of Chemistry and Chemical Engineering, California Institute of Technology, Pasadena, CA 91125

${ }^{\mathrm{b}}$ Chevron Research and Technology Company, Richmond, CA 94802

* To whom correspondence should be addressed. 


\section{Abstract}

A variety of new organic structure-directing agents (SDA's) are synthesized and used for the synthesis of high-silica molecular sieves. The hydrophobicity and rigidity of these new and other previously known SDA's are evaluated in terms of their phase transfer behavior from water to chloroform and the number of tertiary and quaternary connectivities, respectively. It is found that the phase transfer behavior of the organic cation SDA's is best measured when they are in their iodide form in that the greatest ability for discrimination between differences in hydrophobicity is possible in this form of the salt. The phase transfer behavior of numerous SDA's shows the same trend as that of simple tetraalkylammonium iodides with respect to the correlation between $\mathrm{C} / \mathrm{N}^{+}$values and percent transferred. The phase transfer results are correlated to the ability for structuredirection in molecular sieve synthesis. It is difficult to obtain a molecular sieve when using extremely hydrophobic SDA's. For hydrophobic, monocationic SDA's, introduction of a second charge into the molecule decreases the hydrophobicity and allows for structuredirection in molecular sieve synthesis. Thus, SDA's with intermediate hydrophobicity are found to be most useful for high-silica molecular sieve synthesis. In terms of SDA geometry, bulky, rigid molecules with limited conformational variability result in near unique formation of a great variety of new high-silica molecular sieves. The use of relatively flexible molecules with a minimum diameter of approximately $5 \AA$ gives more than one molecular sieve.

Keywords: Structure-directing agents; High-silica molecular sieves; Hydrophobicity; Rigidity; Phase transfer 


\section{Introduction}

It is well known that organic cations such as quaternary ammonium compounds can assist in the crystallization of high-silica molecular sieves by influencing the rates of product formation as well as product selectivity. These effects have been well-documented in previous literature $[1,2]$. The organic molecules can be found inside the pores of the resulting molecular sieve that crystallizes out of solution; these guest organic cations will be called structure-directing agents (SDA's) rather than templates here for reason expounded upon by Davis and Lobo [2]. The actual organic-molecular sieve structure is the outcome of synergystic interactions between the organic cations and the inorganic components that influence the reaction pathway leading to the final outcome of the synthesis. Some of the organic-inorganic interactions observed in molecular sieve synthesis have recently been reviewed by Davis and Zones [3].

With respect to the contribution of the organic cations, it is important to understand the properties of these molecules which influence the type of molecular sieve that will crystallize. Such information then allows for improvements in efforts to generate molecular sieve structures "by design". Here, we report simple correlations for two properties of the organic cations that lead to high-silica molecular sieve synthesis. These correlations should assist in efforts to predict how organic SDA's should influence the outcome of molecular sieve syntheses.

In order to pursue the lofty goal of molecular sieve synthesis by design, it is important to understand the properties of the organic molecules that lead to successful interactions with the inorganic components. To this end, we report here a simple method for determining the relative hydrophobicity of an organic cation and then attempt to correlate the relative hydrophobicity and rigidity of the organic cations to their ability to structure direct the formation of high-silica molecular sieves. 


\section{Experimental Section}

\subsection{Synthesis of organic structure-directing agents as iodide salts (see Table 1)}

All the organics prepared by the methods described below were analyzed by ${ }^{1} \mathrm{H}$ and ${ }^{13} \mathrm{C}$ NMR. Thus, the procedures provided are for the synthesis of pure compounds as verified by NMR analyses.

Dimethyl di-cis-myrtanylammonium iodide (1-iodide), (see Scheme I)

Under an argon atmosphere, a $1 M$ solution of $\mathrm{BH}_{3}$ in tetrahydrofuran (THF, 120

$\mathrm{ml}, 120 \mathrm{mmol}$ ) $[4,5]$ was added dropwise over a period of $45 \mathrm{~min}$ to an ice-cooled solution of (-)- $\beta$-pinene $(28.0 \mathrm{~g}, 206 \mathrm{mmol})$, and the whole was stirred at room temperature for $17 \mathrm{~h}$. Small pieces of ice $(4 \mathrm{~g})$ were added portionwise to hydrolyze the excess borane-THF complex. The reaction mixture was immersed in an ice-bath, $3 \mathrm{~N}$ $\mathrm{NaOH}(50 \mathrm{ml})$ was added, and then $30 \%$ hydrogen peroxide $(30 \mathrm{ml})$ was added over a period of $45 \mathrm{~min}$. The reaction was monitored by thin layer chromatography (t.l.c.) on silica (eluent: $14 \%$ ethyl acetate- $n$-hexane). After stirring at room temperature for an additional $2.8 \mathrm{~h}$, the mixture was diluted with benzene $(200 \mathrm{ml})$ and water $(300 \mathrm{ml})$. The upper organic layer was separated and the aqueous layer was extracted with benzene ( 200 $\mathrm{ml}$ ). The organic layer and the extracts were combined and shaken sequentially with water (300 $\mathrm{ml} \times 2)$ and saturated aqueous $\mathrm{NaCl}(200 \mathrm{ml} \times 2)$, and then dried by addition of $\mathrm{Na}_{2} \mathrm{SO}_{4}(50 \mathrm{~g})$. The inorganic salts were filtered off and the filtrate was evaporated in vacuo to give cis-myrtanol $(31.5 \mathrm{~g}, 99 \%)$ as a colorless oil. The product was further purified by vacuum distillation to give a colorless oil $\left(28.0 \mathrm{~g}, 88 \%\right.$, bp $\left.82-85^{\circ} \mathrm{C} / 1.2 \mathrm{~mm}\right)$.

Under an argon atmosphere, $p$-toluenesulfonyl chloride (tosyl chloride, $38.0 \mathrm{~g}, 199$ $\mathrm{mmol})$ was added to an ice-cooled solution of cis-myrtanol $(25.6 \mathrm{~g}, 166 \mathrm{mmol})$, and the whole was stirred at room temperature for $4.5 \mathrm{~h}$. The reaction was monitored by t.l.c. on 
silica (eluent: benzene). Water $(100 \mathrm{ml})$ was then added to the mixture under ice-cooling, and the whole was stirred at room temperature for $15 \mathrm{~h}$. The mixture was diluted with toluene $(500 \mathrm{ml})$ and the organic layer was shaken sequentially with water $(200 \mathrm{ml}), 10 \%$ aqueous $\mathrm{HCl}$, water (200 ml), saturated aqueous $\mathrm{NaHCO}_{3}(200 \mathrm{ml}$ x 2), and saturated aqueous $\mathrm{NaCl}(200 \mathrm{ml} \times 2)$ in a separatory funnel. The organic solution was dried over $\mathrm{Na}_{2} \mathrm{SO}_{4}(50 \mathrm{~g})$. The inorganic salts were filtered off and the filtrate was evaporated in vacuo to give cis-myrtanyl tosylate $(51.1 \mathrm{~g}, 100 \%)$ as a colorless oil.

A solution of (-)-cis-myrtanylamine $(30.0 \mathrm{~g}, 195 \mathrm{mmol})$ in pyridine $(50 \mathrm{ml})$ was added dropwise to a solution of $p$-toluenesulfonyl chloride (tosyl chloride, $41.0 \mathrm{~g}, 215$ $\mathrm{mmol})$ in pyridine $(100 \mathrm{ml})$ under ice-cooling. The mixture was stirred at room temperature for $4 \mathrm{~h}$. The reaction was monitored by t.l.c. on silica (eluent: chloroform). Water $(80 \mathrm{ml})$ was added under ice-cooling and then the solution was diluted with toluene $(500 \mathrm{ml})$. The organic layer was separated and shaken sequentially with $10 \%$ aqueous $\mathrm{HCl}(200 \mathrm{ml} \times 5)$, water $(200 \mathrm{ml})$, saturated aqueous $\mathrm{NaHCO}_{3}(200 \mathrm{ml})$, and saturated aqueous $\mathrm{NaCl}(200 \mathrm{ml} \times 2)$ in a separatory funnel, and then dried over $\mathrm{Na}_{2} \mathrm{SO}_{4}(50 \mathrm{~g})$. The inorganic salts were removed by filtration and the organic solvents were evaporated in vacuo to give a red brown solid $(57.7 \mathrm{~g})$. Recrystallization from hexane $(60 \mathrm{ml})$ gave $\mathrm{N}$ cis-myrtanyl-p-toluenesulfonamide as pale orange needles $(44.1 \mathrm{~g}, 73 \%)$.

$\mathrm{NaH}(60 \%, 7.8 \mathrm{~g}, 195 \mathrm{mmol})$ was added to a mixture of the $N$-cis-myrtanyl-ptoluenesulfonamide (40.0 g, $130 \mathrm{mmol})$, cis-myrtanyl tosylate $(28.0 \mathrm{~g}, 124 \mathrm{mmol})$ obtained by hydroboration of $\beta$-pinene followed by tosylation as described above, and $N, N$-dimethylformamide $(\mathrm{DMF}, 200 \mathrm{ml})$ at room temperature. The reaction vessel was then heated in an oil bath at $120-135^{\circ} \mathrm{C}$ for $3 \mathrm{~h}$. The reaction was monitored by t.l.c. on silica (eluent: $20 \%$ ethyl acetate- $n$-hexane). Saturated aqueous $\mathrm{NH}_{4} \mathrm{Cl}(60 \mathrm{ml})$ was added under ice-cooling and the mixture was extracted with benzene $(600 \mathrm{ml})$. The combined extract was shaken sequentially with water $(300 \mathrm{ml}$ x 3$)$ and saturated aqueous $\mathrm{NaCl}(300$ $\mathrm{ml})$ in a separatory funnel, and then dried over $\mathrm{Na}_{2} \mathrm{SO}_{4}(60 \mathrm{~g})$. The inorganic salts were 
removed by filtration and the organic solvents were evaporated in vacuo to give a brown oil (54.9 g). This oil consisted of $\beta$-pinene as a side-product, the target $N, N$-di-cis-myrtanyl$p$-toluenesulfonamide, and unreacted $N$-cis-myrtanyl-p-toluenesulfonamide. The oil was applied to the top of a column of silica gel (Merck, Silica gel 60, particle size 0.040-0.063 $\mathrm{mm}, 300 \mathrm{~g}, 40 \mathrm{~mm}$-diam x $600 \mathrm{~mm}$ ) loaded with $6 \%$ ethyl acetate- $n$-hexane solution; the products eluted with this solvent system $(1300 \mathrm{ml})$, and then $9 \%$ ethyl acetate- $n$-hexane $(1500 \mathrm{ml})$. Fractions (total volume $1300 \mathrm{ml}$ ) containing the $N, N$-di-cis-myrtanyl-ptoluenesulfonamide $\left(\mathrm{R}_{\mathrm{f}}=0.50,9 \%\right.$ ethyl acetate- $n$-hexane) were combined and concentrated to give $N, N$-di-cis-myrtanyl-p-toluenesulfonamide $(18.0 \mathrm{~g}, 33 \%)$.

A mixture of $N, N$-di-cis-myrtanyl-p-toluenesulfonamide (11.0 g, $25 \mathrm{mmol})$, phenol $(4.7 \mathrm{~g}, 50 \mathrm{mmol})$ and a $30 \% \mathrm{HBr}$ solution in acetic acid $(25 \mathrm{ml})$ was heated in an oil bath at $80^{\circ} \mathrm{C}$ for $14 \mathrm{~h} \mathrm{[6].} \mathrm{The} \mathrm{reaction} \mathrm{was} \mathrm{monitored} \mathrm{by} \mathrm{t.l.c.} \mathrm{on} \mathrm{silica} \mathrm{(eluent:} 33 \%$ ethyl acetate- $n$-hexane). After cooling to room temperature, benzene (600 ml), water (100 $\mathrm{ml})$, and $\mathrm{NaOH}(120 \mathrm{~g})$ were added and shaken. The organic layer was shaken sequentially with $10 \%$ aqueous $\mathrm{NaOH}(300 \mathrm{ml}$ x 3$)$, water (300 ml) and saturated aqueous $\mathrm{NaCl}(300 \mathrm{ml})$ in a separatory funnel, and then dried over $\mathrm{K}_{2} \mathrm{CO}_{3}(30 \mathrm{~g})$. The inorganic salts were removed by filtration and the organic solvents were evaporated in vacuo to give a brown oil (12.7 g). This oil mainly consisted of di-p-tolyl disulfide [6] and the target secondary amine. The oil was applied to the top of a column of silica gel (Merck, Silica gel 60 , particle size $0.040-0.063 \mathrm{~mm}, 300 \mathrm{~g}, 40 \mathrm{~mm}$-diam x $600 \mathrm{~mm}$ ) loaded with $33 \%$ ethyl acetate- $n$-hexane solution; the products eluted with this solvent system $(800 \mathrm{ml})$, and then 9 $\%$ methanol-chloroform $(1500 \mathrm{ml})$. Fractions (total volume $1400 \mathrm{ml}$ ) containing the target molecule $\left(\mathrm{R}_{\mathrm{f}}=0.30,5 \%\right.$ methanol-chloroform $)$ were combined and concentrated to give di-cis-myrtanylamine as a brown semi-solid (5.3 g, $74 \%)$.

A mixture of di-cis-myrtanylamine $(1.77 \mathrm{~g}, 6.11 \mathrm{mmol}), \mathrm{K}_{2} \mathrm{CO}_{3}(2.5 \mathrm{~g}, 18.1$ mmol), methyl iodide ( $3.6 \mathrm{~g}, 25 \mathrm{mmol})$, and methanol $(10 \mathrm{ml})$ was stirred at room temperature for $44 \mathrm{~h}$. The resulting slurry was diluted with chloroform $(20 \mathrm{ml})$, filtered 
and evaporated in vacuo. The residue was extracted with chloroform (50 ml) and filtered. The filtrate was evaporated to give a white powder $(2.47 \mathrm{~g}, 91 \%)$. Recrystallization from methanol (2 ml)-ethyl ether $(8 \mathrm{ml})$ gave dimethyl di-cis-myrtanylammonium iodide (1iodide) as colorless cubes (2.02 g).

$\operatorname{mp} 262-264{ }^{\circ} \mathrm{C}$ (decomp. $\quad[\alpha]_{\mathrm{D}}^{20}=-2.15^{\circ}\left(\mathrm{c}=2.01, \mathrm{CHCl}_{3}\right)$

Anal. Calcd. for $\mathrm{C}_{22} \mathrm{H}_{40} \mathrm{NI}$ : C, 59.32; H, 9.05; N, 3.14. Found: C, 59.22; H, 8.66; N, 2.80 .

Benzyldimethyl-cis-myrtanylammonium iodide (2-iodide), (see Scheme II)

Benzoyl chloride (33.7 g, $240 \mathrm{mmol}$ ) was added dropwise to a solution of (-)-cismyrtanylamine $(35.0 \mathrm{~g}, 228 \mathrm{mmol})$ in pyridine $(140 \mathrm{ml})$ at room temperature, and the whole was stirred at room temperature for $1.3 \mathrm{~h}$. The reaction was monitored by t.l.c. on silica (eluent: $9 \%$ ethyl acetate-benzene). Water $(35 \mathrm{ml})$ was added to the mixture and stirred at room temperature for $2 \mathrm{~h}$. This mixture was diluted with benzene $(1000 \mathrm{ml})$ and shaken sequentially with water $(500 \mathrm{ml}), 10 \%$ aqueous $\mathrm{HCl}(500 \mathrm{ml}$ x 2), $5 \%$ aqueous $\mathrm{NaOH}(500 \mathrm{ml} \times 2)$, and saturated aqueous $\mathrm{NaCl}(500 \mathrm{ml} \times 2)$ in a separatory funnel, and then dried over $\mathrm{Na}_{2} \mathrm{SO}_{4}(80 \mathrm{~g})$. The inorganic salts were removed by filtration and the organic solvents were evaporated in vacuo to give a pale yellow solid (57.0 g).

Recrystallyzation from $n$-hexane $(70 \mathrm{ml}$ ) gave $N$-cis-myrtanylbenzamide [7] as pale yellow pillars $(54.2 \mathrm{~g}, 92 \%)$.

Under an argon atmosphere, a solution of $\mathrm{N}$-cis-myrtanylbenzamide (54.2 g, 0.21 mol) in tetrahydrofuran (THF, $210 \mathrm{ml}$ ) was added dropwise to a stirred suspension of $\mathrm{LiAlH}_{4}(24.5 \mathrm{~g}, 0.65 \mathrm{~mol})$ in THF $(630 \mathrm{ml})$ at room temperature, and the whole was stirred under reflux for $4 \mathrm{~h}$ [8]. The reaction was monitored by t.l.c. on silica (eluent: 17 $\%$ ethyl acetate-benzene). After cooling the mixture to room temperature, water $(24.5 \mathrm{ml})$ was added dropwise (Caution: Unless water is added slowly, violent reaction will occur.), and then $15 \%$ aqueous $\mathrm{NaOH}(24.5 \mathrm{ml})$ and water $(73.5 \mathrm{ml})$ were added successively and 
stirred for $20 \mathrm{~min}$. The resulting suspension was filtered. The filtrate and washings were combined and evaporated in vacuo. The oily residue was dissolved in benzene $(600 \mathrm{ml})$, dried over $\mathrm{K}_{2} \mathrm{CO}_{3}(30 \mathrm{~g})$, and filtered again. Evaporation of the filtrate to dryness in vacuo gave benzyl cis-myrtanylamine $(51.3 \mathrm{~g}, 100 \%)$ as a yellow oil.

Methyl iodide (119 g, $0.84 \mathrm{~mol}$ ) was added dropwise to a mixture of benzyl cismyrtanylamine $(51.0 \mathrm{~g}, 0.21 \mathrm{~mol}), \mathrm{K}_{2} \mathrm{CO}_{3}(64.0 \mathrm{~g}, 0.46 \mathrm{~mol})$, and methanol $(350 \mathrm{ml})$, and the whole was stirred at room temperature for $67 \mathrm{~h}$ and filtered. The filtrate was evaporated in vacuo and the residue was extracted with chloroform, and then filtered. This procedure was then repeated. Evaporation in vacuo gave a yellow oil, which was dissolved in a mixture of methanol $(18 \mathrm{ml})$ and ethyl acetate $(88 \mathrm{ml})$ by heating to $70{ }^{\circ} \mathrm{C}$. After cooling to room temperature and adding seed obtained from another run, crystals separated out slowly. Ethyl ether $(30 \mathrm{ml})$ was added slowly to make crystals develop. The crystals were collected by filtration and washed with ethyl acetate and small amount of methanol. Benzyldimethyl-cis-myrtanylammonium iodide (2-iodide) was obtained as pale yellow pillars $(68.2 \mathrm{~g}, 81 \%)$.

$\operatorname{mp~} 167-169^{\circ} \mathrm{C} \quad[\alpha]_{\mathrm{D}}^{20}=-1.96^{\circ}(\mathrm{c}=1.02, \mathrm{MeOH})$ Anal. Calcd. for $\mathrm{C}_{19} \mathrm{H}_{30} \mathrm{NI}$ : C, 57.14; H, 7.57; N, 3.51. Found: C, 57.16; H, 7.36; N, 3.46 .

Dibenzyldimethylammonium iodide (3-iodide) [9]

Methyl iodide $(85.0 \mathrm{~g}, 600 \mathrm{mmol})$ was added to a mixture of dibenzylamine (40.0 $\mathrm{g}, 203 \mathrm{mmol}), \mathrm{K}_{2} \mathrm{CO}_{3}(69.0 \mathrm{~g}, 500 \mathrm{mmol})$, and methanol $(400 \mathrm{ml})$, and the whole was stirred at room temperature for $45 \mathrm{~h}$. Chloroform $(100 \mathrm{ml})$ was added to the mixture and filtered. The solvents were removed from the filtrate by evaporation in vacuo. The residue was extracted with chloroform $(500 \mathrm{ml})$ and filtered. The filtrate was evaporated in vacuo to give a colorless oil. A white solid (52.1 g) was obtained by addition of ethyl ether followed by drying. Recrystallization of the solid from methanol(60 ml)-THF(120 ml)- 
ethyl ether $(100 \mathrm{ml})$ gave dibenzyldimethylammonium iodide (3-iodide) colorless needles $(48.9 \mathrm{~g}, 68 \%)$.

mp 194-196 ${ }^{\circ} \mathrm{C}$ (decomp.)

Anal. Calcd. for $\mathrm{C}_{16} \mathrm{H}_{20} \mathrm{NI} \bullet 1 / 4 \mathrm{H}_{2} \mathrm{O}$ : C, 53.71; H, 5.78; N, 3.92. Found: C, 53.40; H, $5.76 ; \mathrm{N}, 3.64$.

Triethyl-cis-myrtanylammonium iodide (4-iodide)

Ethyl iodide (20.8 g, $133 \mathrm{mmol})$ was added to a mixture of (-)-cis-myrtanylamine $(5.1 \mathrm{~g}, 33.3 \mathrm{mmol}), \mathrm{K}_{2} \mathrm{CO}_{3}(13.8 \mathrm{~g}, 99.9 \mathrm{mmol})$, and methanol $(66 \mathrm{ml})$, and the whole was stirred under reflux for $24 \mathrm{~h}$. Chloroform $(30 \mathrm{ml})$ was then added to the mixture. After filtration and evaporation in vacuo, the residue was extracted with chloroform (100 $\mathrm{ml}$ ), and then filtered again. After evaporation in vacuo, the resulting cloudy solution was diluted with chloroform $(100 \mathrm{ml})$. Filtration and evaporation in vacuo gave a white solid $(7.29 \mathrm{~g}, 60 \%)$. Recrystallization from methanol $(4 \mathrm{ml})$-ethyl ether $(10 \mathrm{ml})$ gave pure triethyl-cis-myrtanylammonium iodide (4-iodide) as colorless fine needles (6.54 g). $\operatorname{mp~} 189-190^{\circ} \mathrm{C} \quad[\alpha]_{\mathrm{D}}^{20}=-1.37^{\circ}\left(\mathrm{c}=2.49, \mathrm{CHCl}_{3}\right)$ Anal. Calcd. for $\mathrm{C}_{16} \mathrm{H}_{32} \mathrm{NI}$ : C, 52.60; H, 8.83; N, 3.83. Found: C, 52.88; H, 9.03; N, 3.83.

Trimethyl-cis-myrtanylammonium iodide (5a-iodide) was prepared by quaternization of (-)-cis-myrtanylamine with methyl iodide by a known method [10]. $\operatorname{mp} 275-278^{\circ} \mathrm{C}$ (decomp.) $\quad[\alpha]_{\mathrm{D}}^{20}=-1.90^{\circ}(\mathrm{c}=1.05, \mathrm{MeOH})$

Trimethyl-trans-myrtanylammonium iodide (5b-iodide)

A solution of diethyl azodicarboxylate (DEAD, $12.4 \mathrm{~g}, 71.3 \mathrm{mmol})$ [11] in THF $(50 \mathrm{ml})$ was added dropwise to a mixture of (-)-trans-myrtanol $(10.0 \mathrm{~g}, 64.8 \mathrm{mmol})$, triphenylphosphine $(18.7 \mathrm{~g}, 71.3 \mathrm{mmol})$, phthalimide $(10.5 \mathrm{~g}, 71.3 \mathrm{mmol})$, and THF (100 
$\mathrm{ml}$ ) under ice-cooling. The resulting yellow solution was stirred at room temperature for 22 h. The reaction was monitored by t.l.c. on silica (eluent: $14 \%$ ethyl acetate- $n$-hexane). Evaporation to dryness in vacuo and addition of ethyl ether $(100 \mathrm{ml})$ resulted the precipitation of a white solid. After filtration, the white residue was washed with ethyl ether $(100 \mathrm{ml})$. From the combined filtrate, large colorless pillars separated out. The crystalline compound was diethyl hydrazinedicarboxylate which was filtered off. The mother liquor was concentrated to give a yellow solid. The oil was applied to the top of a column of silica gel (Merck, Silica gel 60, particle size 0.040-0.063 mm, 80 g, 29 mmdiam x $330 \mathrm{~mm}$ ) loaded with chloroform $(3 \mathrm{ml})$ solution; the products eluted with $9 \%$ ethyl acetate- $n$-hexane $(330 \mathrm{ml})$, and then $14 \%$ ethyl acetate- $n$-hexane $(280 \mathrm{ml})$. Fractions (total volume $340 \mathrm{ml})$ containing the target molecule $\left(\mathrm{R}_{\mathrm{f}}=0.40,14 \%\right.$ ethyl acetate- $n$-hexane $)$ were combined and concentrated to give $N$-trans-myrtanyl phthalimide as a white solid $(18.9 \mathrm{~g}, 100 \%)$. Recrystallization from $n$-hexane $(50 \mathrm{ml})$ gave colorless large pillars (16.1 g).

Hydrazine hydrate $(13.3 \mathrm{~g})$ was added to a solution of trans-myrtanyl phthalimide $(15.0 \mathrm{~g}, 52.9 \mathrm{mmol})$ in methanol $(300 \mathrm{ml})$, and the whole was stirred under reflux for 1.5 h. After evaporating the solvent, ethanol $(300 \mathrm{ml})$ was added and evaporated again. To the resulting white residue, $10 \%$ aqueous $\mathrm{HCl}(100 \mathrm{ml})$ was added and stirred under reflux for 15 min. The reaction was monitored by t.l.c. on silica (eluent: $20 \%$ methanolchloroform). The mixture was filtered and the residue was washed with water $(200 \mathrm{ml})$. The combined filtrate and washings were shaken with dichloromethane $(200 \mathrm{ml} \times 3)$ in a separatory funnel and the aqueous layer was basified by addition of $50 \%$ aqueous $\mathrm{NaOH}$ $(20 \mathrm{ml})$ to $\mathrm{pH}>11$. This solution was extracted with dichloromethane $(250 \mathrm{ml} \mathrm{x} 3)$ and the combined extracts were shaken with water $(100 \mathrm{ml})$ and sturated aqeous $\mathrm{NaCl}(200 \mathrm{ml})$ in a separatory funnel, and then dried over $\mathrm{K}_{2} \mathrm{CO}_{3}(30 \mathrm{~g})$. The inorganic salts were removed by filtration and the organic solvents were evaporated in vacuo to give transmyrtanylamine as a colorless oil $(6.91 \mathrm{~g}, 85 \%)$. 
Methyl iodide ( $28.4 \mathrm{~g}, 200 \mathrm{mmol})$ was added to a mixture of trans-myrtanylamine (6.86 g, $45 \mathrm{mmol}), \mathrm{K}_{2} \mathrm{CO}_{3}(13.8 \mathrm{~g}, 100 \mathrm{mmol})$, and methanol (100 ml), and the whole was stirred at room temperature for $22 \mathrm{~h}$. After filtration and evaporation in vacuo, the residue was extracted with chloroform $(200 \mathrm{ml})$, and then filtered again. After evaporation in vacuo, the resulting cloudy solution was diluted with chloroform $(200 \mathrm{ml})$. Filtration and evaporation in vacuo gave trimethyl-trans-myrtanylammonium iodide (5b-iodide) as a white solid (11.51 g, $80 \%)$. Recrystallization of the solid (8.27 g) from methanol-THFethyl ether gave colorless needles $(7.02 \mathrm{~g})$.

mp 272-274 ${ }^{\circ} \mathrm{C}$ (decomp. $) \quad[\alpha]_{\mathrm{D}}^{20}=-0.08^{\circ}\left(\mathrm{c}=2.60, \mathrm{CHCl}_{3}\right)$

Anal. Calcd. for $\mathrm{C}_{13} \mathrm{H}_{26} \mathrm{NI}$ : C, 48.30; H, 8.11; N, 4.33. Found: C, 48.59; H, 8.38; N, 4.07 .

[(1,1-Dimethyl-4-piperidinium)methyl]dimethyl-cis-myrtanylammonium diiodide (6-diiodide)

Carbobenzoxy chloride $(30.2 \mathrm{~g}, 177 \mathrm{mmol})$ and $2 \mathrm{~N} \mathrm{NaOH}(98 \mathrm{ml})$ were added dropwise at the same time over a period of $15 \mathrm{~min}$ to a solution of isonipecotic acid (20.0 $\mathrm{g}, 155 \mathrm{mmol}$ ) in $2 \mathrm{~N} \mathrm{NaOH}$ (78 ml) under ice-cooling, and the whole was stirred at room temperature for $4 \mathrm{~h}$. The mixture was shaken with ethyl ether $(150 \mathrm{ml} \times 2)$ in a separatory funnel and the aqueous solution was acidified with concentrated hydrochloric acid (15 ml) under ice-cooling, and then extracted with ethyl acetate $(200 \mathrm{ml} \mathrm{x} \mathrm{3).} \mathrm{The} \mathrm{combined}$ extracts were shaken with water $(300 \mathrm{ml})$ and saturated aqueous $\mathrm{NaCl}(300 \mathrm{ml} \times 2)$. The organic layer was dried over $\mathrm{Na}_{2} \mathrm{SO}_{4}(50 \mathrm{~g})$. The inorganic salts were removed by filtration and the solvent was evaporated in vacuo to give $N$-carbobenzoxyisonipecotic acid as a colorless oil $(40.7 \mathrm{~g}, 100 \%)$.

Isobutyl chloroformate $(9.7 \mathrm{~g}, 70.8 \mathrm{mmol})$ was added dropwise to a solution of $N$ carbobenzoxyisonipecotic acid $(16.1 \mathrm{~g}, 61.0 \mathrm{mmol})$ and triethylamine $(7.2 \mathrm{~g}, 70.8 \mathrm{mmol})$ in dichloromethane $(70 \mathrm{ml})$ under ice-cooling and the mixture was stirred at $0{ }^{\circ} \mathrm{C}$ for 10 
min. To this mixture was added (-)-cis-myrtanylamine (10.0 g, $64.9 \mathrm{mmol})$ in dichloromethane $(10 \mathrm{ml})$ and the whole was stirred at room temperature for $11 \mathrm{~h}$. The reaction was monitored by t.l.c. on silica (eluent: $50 \%$ ethyl acetate- $n$-hexane). The mixture was then diluted with dichloromethane $(300 \mathrm{ml})$ and shaken sequentially with $10 \%$ aqueous $\mathrm{HCl}(200 \mathrm{ml})$, water $(200 \mathrm{ml})$, saturated aqueous $\mathrm{NaHCO}_{3}(200 \mathrm{ml}$ x 2) and saturated aqueous $\mathrm{NaCl}(200 \mathrm{ml})$ in a separatory funnel, and then dried over $\mathrm{Na}_{2} \mathrm{SO}_{4}(30$ g). The inorganic salts were removed by filtration and the organic solvents were evaporated in vacuo to give a colorless oil $(34.0 \mathrm{~g})$. The oil was applied to the top of a column of silica gel (Merck, Silica gel 60, particle size 0.040-0.063 mm, 300 g, $40 \mathrm{~mm}$ diam x $600 \mathrm{~mm}$ ) loaded with $50 \%$ ethyl acetate- $n$-hexane solution; the products eluted with this solvent system $(500 \mathrm{ml}), 60 \%$ ethyl acetate- $n$-hexane $(500 \mathrm{ml})$, and then $67 \%$ ethyl acetate- $n$-hexane $(500 \mathrm{ml})$. Fractions (total volume $800 \mathrm{ml}$ ) containing the target molecule $\left(\mathrm{R}_{\mathrm{f}}=0.30,50 \%\right.$ ethyl acetate- $n$-hexane $)$ were combined and concentrated to give a colorless oil. Seeds obtained during the column chromatography were added to the oil and allowed to stand overnight. The crystals separated out were collected by filtration, and then washed with $n$-hexane to give $N$-cis-myrtanyl-4-(1-carbobenzoxy)piperidinecarboxamide as colorless needles $(21.7 \mathrm{~g}, 89 \%)$.

A solution of $N$-cis-myrtanyl-4-(1-carbobenzoxy)piperidinecarboxamide $(23.4 \mathrm{~g}$, $58.7 \mathrm{mmol})$ in acetic acid $(12 \mathrm{ml})$ was mixed with $30 \% \mathrm{HBr}$ solution in acetic acid $(60 \mathrm{ml})$ under ice-cooling and the whole was stirred at room temperature for $2.5 \mathrm{~h} \mathrm{[8].} \mathrm{The}$ reaction was monitored by t.l.c. on silica (eluent: $10 \%$ methanol-chloroform). Ice-cold water (200 ml) was added to the mixture and the resulting solution was shaken with ethyl ether $(100 \mathrm{ml} \times 3)$ in a separatory funnel. The aqueous layer was basified by slow addition of $\mathrm{K}_{2} \mathrm{CO}_{3}$ (ca. $100 \mathrm{~g}$ ) to $\mathrm{pH}>10$ under ice-cooling, and was extracted with dichloromethane ( $300 \mathrm{ml} \times 3)$. The organic extracts were combined, shaken sequentially with saturated aqueous $\mathrm{NaCl}(300 \mathrm{ml} \mathrm{x2})$ in a separatory funnel, dried over $\mathrm{K}_{2} \mathrm{CO}_{3}(50 \mathrm{~g})$, 
and evaporated in vacuo to give cis-myrtanylisonipecotamide $(12.8 \mathrm{~g}, 82 \%)$ as a white solid.

Under an argon atmosphere, a solution of cis-myrtanylisonipecotamide $(9.20 \mathrm{~g}$, $34.8 \mathrm{mmol})$ in THF $(120 \mathrm{ml})$ was added dropwise to a stirred suspension of $\mathrm{LiAlH}_{4}(8.35$ $\mathrm{g}, 220 \mathrm{mmol})$ in THF $(100 \mathrm{ml})$ at room temperature, and the whole was stirred under reflux for $16 \mathrm{~h}$. The reaction was monitored by t.l.c. on silica (eluent: $56 \%$ ethyl acetate$28 \%$ acetic acid- $8 \%$ acetone- $8 \%$ water $)$. Under stirring, water $(8.35 \mathrm{ml})$ was added dropwise, and then $15 \%$ aqueous $\mathrm{NaOH}(8.35 \mathrm{ml})$ and water $(20.05 \mathrm{ml})$ were added successively to the reaction mixture, and the whole was filtered. The filtrate and THF washings were combined and evaporated to dryness in vacuo to give cis-myrtanyl-4piperidinomethylamine $(8.7 \mathrm{~g}, 100 \%)$ as a colorless oil.

Methyl iodide (49.3 g, $347 \mathrm{mmol})$ was added dropwise to a mixture of cismyrtanyl-4-piperidinomethylamine (8.7 g, $34.7 \mathrm{mmol}), \mathrm{K}_{2} \mathrm{CO}_{3}(19.2 \mathrm{~g}, 139 \mathrm{mmol})$, and methanol $(150 \mathrm{ml})$, and the whole was stirred at room temperature for $24 \mathrm{~h}$. The mixture was filtered and the residue was washed with chloroform-methanol $(4: 1,250 \mathrm{ml})$. The filtrate and washings were combined and evaporated to dryness in vacuo. The residue was extracted with chloroform-methanol $(4: 1,250 \mathrm{ml})$ and filtered. The filtrate became cloudy during concentration. Filtration and concentration were repeated until the concentrated solution was no longer cloudy. Evaporation to dryness in vacuo gave [(1,1-dimethyl-4piperidinium)methyl]dimethyl-cis-myrtanylammonium diiodide (6-diiodide) (15.4 g, $79 \%$ ) as a white solid. Recrystalization from methanol-ethyl acetate (1:2) gave colorless tight plates.

$\operatorname{mp} 248-250^{\circ} \mathrm{C}$ (decomp.) $\quad[\alpha]_{\mathrm{D}}^{20}=-1.19^{\circ}(\mathrm{c}=3.37, \mathrm{MeOH})$ Anal. Calcd. for $\mathrm{C}_{20} \mathrm{H}_{40} \mathrm{~N}_{2} \mathrm{I}_{2}$ : C, 42.72; H, 7.17; N, 4.98. Found: C, 42.66; H, 7.13; N, 4.74. 
Benzyl[(1,1-dimethyl-4-piperidinium)methyl]dimethylammonium diiodide (7-diiodide)

Isobutyl chloroformate $(8.44 \mathrm{~g}, 61.8 \mathrm{mmol})$ was added dropwise to a solution of $\mathrm{N}$-carbobenzoxyisonipecotic acid $(12.5 \mathrm{~g}, 47.5 \mathrm{mmol})$ and triethylamine $(6.25 \mathrm{~g}, 61.8$ $\mathrm{mmol}$ ) in dichloromethane $(60 \mathrm{ml})$ under ice-cooling, and the whole was stirred for $50 \mathrm{~min}$. To this mixture was added a solution of benzylamine $(6.11 \mathrm{~g}, 57.0 \mathrm{mmol})$ in dichloromethane $(10 \mathrm{ml})$ under ice-cooling, and the whole was stirred at room temperature for $2 \mathrm{~h}$. The reaction was monitored by t.l.c. on silica (eluent: $50 \%$ ethyl acetate- $n$ hexane). The mixture was diluted with dichloromethane $(300 \mathrm{ml})$ and shaken sequentially with $10 \%$ aqueous $\mathrm{HCl}\left(150 \mathrm{ml}\right.$ x 2), water $(150 \mathrm{ml})$, saturated aqueous $\mathrm{NaHCO}_{3}(150 \mathrm{ml}$ $\mathrm{x} 2)$, and saturated aqueous $\mathrm{NaCl}(150 \mathrm{ml})$ in a separatory funnel, and then dried over $\mathrm{Na}_{2} \mathrm{SO}_{4}(25 \mathrm{~g})$. The inorganic salts were removed by filtration and the organic solvents were evaporated in vacuo to give a white solid $(18.37 \mathrm{~g})$, which was recrystallized from ethyl acetate $(5 \mathrm{ml})-n$-hexane $(10 \mathrm{ml})$ to give $N$-benzyl-4-(1carbobenzoxy)piperidinecarboxamide as a white powder $(11.50 \mathrm{~g}, 69 \%)$.

A solution of $N$-benzyl-4-(1-carbobenzoxy)piperidinecarboxamide (11.4 g, 32.3 $\mathrm{mmol})$ in acetic acid $(7 \mathrm{ml})$ was mixed with a $30 \% \mathrm{HBr}$ solution in acetic acid $(35 \mathrm{ml})$ under ice-cooling and the whole was stirred at room temperature for $3 \mathrm{~h}$. The reaction was monitored by t.l.c. on silica (eluent: $10 \%$ methanol-chloroform). Ice-cold water (100 ml) was added to the mixture and the resulting solution was shaken with ethyl ether $(100 \mathrm{ml} \mathrm{x}$ 3 ) in a separatory funnel. The aqueous layer was basified by slow addition of $25 \%$ aqueous $\mathrm{NaOH}(120 \mathrm{ml})$ under ice-cooling, and was extracted with dichloromethane (300 $\mathrm{ml} \times \mathrm{x}$ ). The organic extracts were combined, shaken with saturated aqueous $\mathrm{NaCl}$ (300 $\mathrm{ml} \times 2)$ in a separatory funnel, dried over $\mathrm{K}_{2} \mathrm{CO}_{3}(40 \mathrm{~g})$, and evaporated to give benzylisonipecotamide (5.95 $\mathrm{g}, 84 \%)$ as a white solid.

Under an argon atmosphere, a solution of benzylisonipecotamide ( $5.95 \mathrm{~g}, 27.3$ $\mathrm{mmol})$ in THF (60 ml) was added dropwise to a stirred suspension of $\mathrm{LiAlH}_{4}(6.23 \mathrm{~g}, 164$ $\mathrm{mmol})$ in THF (100 ml) at room temperature, and the whole was stirred under reflux for 
16.5 h. The reaction was monitored by t.l.c. on silica (eluent: $56 \%$ ethyl acetate- $28 \%$ acetic acid- $8 \%$ acetone- $8 \%$ water $)$. Under stirring, water $(8.3 \mathrm{ml})$ was added dropwise, and then $15 \%$ aqueous $\mathrm{NaOH}(8.3 \mathrm{ml})$ and water $(24.9 \mathrm{ml})$ were added successively to the reaction mixture, and the whole was filtered. The filtrate and THF washings were combined and evaporated to dryness in vacuo to give benzyl-4-piperidinomethylamine $(5.56 \mathrm{~g}, 100 \%)$ as a colorless oil.

Methyl iodide (39.5 g, $278 \mathrm{mmol}$ ) was added to a mixture of benzyl-4piperidinomethylamine $(5.56 \mathrm{~g}, 27.2 \mathrm{mmol}), \mathrm{K}_{2} \mathrm{CO}_{3}(15.4 \mathrm{~g}, 111 \mathrm{mmol})$, and methanol $(100 \mathrm{ml})$, and the whole was stirred at room temperature for $49 \mathrm{~h}$. The mixture was filtered and the residue was washed with chloroform-methanol $(2: 1,250 \mathrm{ml})$. The filtrate and washings were combined and evaporated to dryness in vacuo. The residue was extracted with chloroform-methanol $(2: 1,250 \mathrm{ml})$ and filtered. The filtrate became cloudy during concentration. Filtration and concentration were repeated until the concentrated solution was no longer cloudy. Evaporation to dryness in vacuo gave white amorphous (19.6 g). Recrystallization from methanol $(6 \mathrm{ml})$-ethyl acetate $(12 \mathrm{ml})$ gave benzyl[(1,1-dimethyl-4piperidinium)methyl]dimethylammonium diiodide (7-diiodide) (11.3 g, 80 \%) as colorless tight plates.

mp 205-207 ${ }^{\circ} \mathrm{C}$ (decomp.)

Anal. Calcd. for $\mathrm{C}_{17} \mathrm{H}_{30} \mathrm{~N}_{2} \mathrm{I}_{2} \bullet 1 / 2 \mathrm{H}_{2} \mathrm{O}: \mathrm{C}, 38.84 ; \mathrm{H}, 5.95 ; \mathrm{N}, 5.33$. Found: C, 38.73; H, $5.81 ; \mathrm{N}, 5.25$.

Trimethylmyrtenylammonium iodide (9-iodide)

Sodium cyanoborohydride $(8.32 \mathrm{~g}, 132 \mathrm{mmol})$ [12] was added to a mixture of (-)myrtenal $(15.0 \mathrm{~g}, 100 \mathrm{mmol})$ and a $2.0 \mathrm{M}$ solution of dimethylamine in methanol $(76 \mathrm{ml})$ under ice-cooling, and the whole was stirred at room temperature for $21 \mathrm{~h}$. The reaction was monitored by t.l.c. on silica (eluent: $50 \%$ ethyl acetate-benzene). The solvent was evaporated in vacuo and the residue was extracted with benzene $(400 \mathrm{ml})$. The combined 
extracts were shaken sequentially with water $(200 \mathrm{ml}$ x2) and saturated aqueous $\mathrm{NaCl}(200$ $\mathrm{ml})$ in a separatory funnel, and then dried over $\mathrm{Na}_{2} \mathrm{SO}_{4}(30 \mathrm{~g})$. The inorganic salts were removed by filtration and the organic solvents were evaporated in vacuo to give a colorless oil which was then dissolved in ethyl acetate $(150 \mathrm{ml})$. To this solution was added methyl iodide $(28.4 \mathrm{~g}, 200 \mathrm{mmol})$ under ice-cooling, and the whole was stirred at room temperature for $17 \mathrm{~h}$. Precipitation was observed within $1 \mathrm{~min}$. The pale yellow solid product formed was filtered and washed with ethyl acetate $(100 \mathrm{ml})$. The recovered solid $(22 \mathrm{~g})$ was recrystallized from methanol $(5 \mathrm{ml})$-ethyl acetate $(15 \mathrm{ml})$ to give trimethylmyrtenylammonium iodide (9-iodide) as colorless scales (12.6 g, $39 \%$ ). $\operatorname{mp} 212-213^{\circ} \mathrm{C}$ (decomp. $\quad[\alpha]_{\mathrm{D}}^{20}=-2.06^{\circ}(\mathrm{c}=4.69, \mathrm{MeOH})$ Anal. Calcd. for $\mathrm{C}_{13} \mathrm{H}_{24} \mathrm{NI}$ : C, 48.61; H, 7.53; N, 4.36. Found: C, 48.65; H, 7.45; N, 4.19 .

Compound $\mathbf{8}$ was purchased from Aldrich.

Compound 10 was synthesized by Nakagawa [13].

11 was prepared from the 9-keto[3.3.1]bicyclononane, using the Leuckart method to generate the tertiary amine $[14,15]$.

12 was prepared by exhaustive ethylation as described for 4 .

The spirocyclic 13 was prepared by cyclization of 1,4-diiodobutane onto the secondary amine of 3-azabicyclo[3.2.2]nonane, carrying out the reaction in dilute solutions [16].

14 was prepared from a sequence of reactions described by Nakagawa after forming the carbocyclic skeleton using the Diels-Alder reaction for 1,3-cyclohexadiene and $N$-methylmaleimide $[17,18]$.

The ethylation of 3,5-dimethylpiperidine was carried out as in $\mathbf{4}$ and $\mathbf{1 2}$ to lead to compound $\mathbf{1 5}$. 
16 was prepared by exhaustive methylation of 1-adamantanamine, using methods for compound $\mathbf{5}$.

17 and 19 were derived from their keto starting components using the Leuckart approach $[14,15]$.

The diquaternary ammonium propellane 18 was formed in a multi-step synthesis [19] built around the Weiss reaction.

Quaternization of commercially available sparteine leads to 20 [20]. It is quite difficult to alkylate the second nitrogen due to the steric hindrance. In other words, N-16 can be selectively quaternized.

\subsection{Anion exchange from iodide to hydroxide}

Example of procedure I

Amberlite IRA-400(OH) (Aldrich) anion exchange resin $(150 \mathrm{ml}$, corresponding to $210 \mathrm{mmol}$ of exchange capacity) was added to a suspension of dimethyl cismyrtanylbenzylammonium iodide (2-iodide) $(19.5 \mathrm{~g}, 48.8 \mathrm{mmol})$ in water $(700 \mathrm{ml})$ and the whole was stirred at room temperature for $22 \mathrm{~h}$. Crystals of the iodide disappeared within $10 \mathrm{~min}$. After filtration, the aqueous solution was concentrated to $100 \mathrm{ml}$ to give $0.447 \mathrm{M}$ of dimethyl cis-myrtanylbenzylammonium hydroxide (2-hydroxide) based on titration of the resulting solution. The yield was $91.7 \%$.

Example of procedure II

[(1,1-Dimethyl-4-piperidinium)methyl]dimethyl-cis-myrtanylammonium diiodide (6-diiodide) (12.03 g, $21.4 \mathrm{mmol}$ ) was dissolved in water $(80 \mathrm{ml})$ and was passed through an ion-exchange resin (150 ml, corresponding to $210 \mathrm{mmol}$ of exchange capacity) packed in a column. Fractions of $\mathrm{pH}>8$ were collected and the aqueous solution was concentrated 
to $100 \mathrm{ml}$ to give $0.410 \mathrm{M}\left(\mathrm{as} \mathrm{OH}^{-}\right)$of [(1,1-dimethyl-4-piperidinium)methyl]dimethyl-cismyrtanylammonium dihydroxide (6-dihydroxide) based on titration of the resulting solution. The yield was $95.8 \%$.

\subsection{Partition of organocations between water and chloroform}

Procedure for symmetric tetraalkylammonium iodides and bromides and other organic iodides

Weighed dry salt (1-2 mmol) was dissolved in a mixture of water $(35 \mathrm{ml})$ and chloroform $(35 \mathrm{ml})$. After more than $24 \mathrm{~h}$, the two phases were separated and the chloroform layer was dried over $\mathrm{Na}_{2} \mathrm{SO}_{4}(3.0 \mathrm{~g})$. After suction filtration and washing of the residue with chloroform $(5 \mathrm{ml})$, the combined filtrate and washings were evaporated in vacuo. Benzene $(5 \mathrm{ml})$ was added in order to solidify oily residues, and the solvents were removed completely in vacuo. The dried solid was weighed.

Procedure for tetraalkylammonium hydroxides

$\mathrm{D}_{2} \mathrm{O}$ was added to an aqueous solution of hydroxide $(1 \mathrm{mmol})$ to make $10 \mathrm{ml}$ of total volume. $\mathrm{CDCl}_{3}(10 \mathrm{ml})$ was added to the mixture. After $24 \mathrm{~h}$, the two phases were separated. Precisely weighed 1,3,5-tribromobenzene (ca.30 mg) and 3(trimethylsilyl)propionic-2,2,3,3- $d_{4}$ acid, sodium salt (TSP, ca.100 mg) were dissolved in the $\mathrm{CDCl}_{3}$ and aqueous layers, respectively and used as internal standards. The quantity of tetraalkylammonium hydroxide in each layer was determined by ${ }^{1} \mathrm{H}$ NMR. 


\subsection{Molecular sieve synthesis}

High-silica molecular sieves were synthesized from gels of composition $50 \mathrm{SiO}_{2}$ $\mathrm{xM}_{2} \mathrm{O}_{3}-10 \mathrm{R}-\mathrm{yNaOH}-\mathrm{zH}_{2} \mathrm{O}$ where $\mathrm{M}$ is $\mathrm{B}$ or $\mathrm{Al}, \mathrm{R}$ is the organic SDA in the hydroxide form and $0<x<2,5<y<10$ and $2500<z<5000$. The synthesis temperatures were 135,150 and $175^{\circ} \mathrm{C}$. A typical synthesis of a borosilicate molecular sieve used a gel composition where $\mathrm{x}=1, \mathrm{y}=5$ and $\mathrm{z}=3100$ and was carried out as follows: sodium borate decahydrate $\left(\mathrm{Na}_{2} \mathrm{~B}_{4} \mathrm{O}_{7} \cdot 10 \mathrm{H}_{2} \mathrm{O}\right.$, Fisher, $\left.65 \mathrm{mg}, 0.17 \mathrm{mmol}\right), \mathrm{NaOH}(67 \mathrm{mg}, 1.67 \mathrm{mmol})$, and a 0.179 $M$ aqueous solution of trimethylmyrtenylammonium hydroxide $(\mathbf{9}, 18.7 \mathrm{ml}, 3.34 \mathrm{mmol})$ were mixed and stirred at room temperature for $1 \mathrm{~h}$. Fumed silica (Cab-O-Sil, M-5, $1.0 \mathrm{~g}$, $16.7 \mathrm{mmol}$ ) was then added and and stirred until a homogeneous gel was obtained. In some syntheses, as-synthesized boron-substituted zeolite beta (amount equal to 1 2\% of recovered solids) was added to the gel [20]. The mixture was subsequently sealed in puresilica glass tubes $(\sim 75 \mathrm{~mm} \times 12 \mathrm{~mm}$ diam). The synthesis was carried out statically in a convection oven at $150{ }^{\circ} \mathrm{C}$. The white crystals were recovered by filtration, washed with water and acetone and dried in air at room temperature. Phase identification was made by powder X-ray diffraction (XRD) with a Scintag XDS 2000 diffractometer using Cu-K $\alpha$ radiation and a solid-state Ge detector.

\section{Results and Discussion}

During the synthesis of the molecular sieve, organic species that are initially in aqueous solution ultimately end up in the hydrophobic pores of the molecular sieve. The host lattice can be considered hydrophobic when it is mostly $\mathrm{SiO}_{2}$. Thus, the thermodynamic stability of the composite guest/host material is enhanced over the stability of a physical mixture of the individual components [21]. Additionally, it is known that for 
high-silica molecular sieves, the enthalpy of formation does not vary more than 2RT (RT: thermal energy) from amorphous silica for all structures within the current limits of framework density [22]. The organic SDA's can have dramatic influences on the synthetic pathways of molecular sieves even though their interactions with the inorganic framework are via non-covalent bonds much in the same way as a large number of weak interactions can have profound influences on structure and/or function of biological macromolecules. Here, we investigate two properties of SDA's, namely hydrophobicity and rigidity, and attempt to correlate these properties with the SDA's ability to produce crystalline microporous materials. Hydrophobic organic cations, typically not capable of hydrogen bonding, promote the ordering of water molecules around themselves when placed in aqueous media [23]. This ordering results in reduced degrees of freedom for the water molecules. Thus, these types of organo-cations have sometimes been termed "structure breakers" for this effect. One can imagine an even poorer fit for the SDA in water given the high ionic strength of most molecular sieve synthesis solutions. Upon addition of silicates, these entities can displace the locally ordered water. Additionally, for charge-compensation purposes, the cationic charge of the SDA can interact with silicate anions; in that sense there is an opportunity to restructure the silicates locally. These types of interactions were recently observed by Burkett and Davis [24-26].

Although most SDA's are soluble in water, studies on the lower tetraalkylammonium homologues, TMA, TEA, and TPA, indicate that solvation of TMA is hydrophilic, TEA has mixed character, and TPA $\left(\mathrm{C} / \mathrm{N}^{+}=12\right)$ already generates hydrophobic solvation around the propyl hydrocarbon chains [27]. In order to estimate the relative hydrophobicity of various tetraalkylammonium compounds, we examined their transport from water to chloroform using a procedure recently described by Zones et al. [28]. Although the hydroxide form of the SDA is often used in molecular sieve synthesis, we examined bromides and iodides as well. The hydroxides are usually prepared from their halogen precursors. Transfer percentage of each molecule is plotted as a function of its 
$\mathrm{C} / \mathrm{N}^{+}$ratio and is shown in Figure 1 . It is known that the quaternary ammonium salts are soluble in organic solvents with iodides $>$ bromides $>$ chlorides [29] and our results agree with this trend. For larger, carbon-rich cations, the iodides will also tend to form better tight-ion pairs with the polarizabilities of cation and anion charge better matched. This leads to more favorable transport into lower dielectric constant media.

There are no transport differences observed for TMA, TEA and TPA when they are as hydroxide salts and each fails to partition into chloroform. Therefore, the testing of these hydroxide salts does not reflect the differences in chemical character for TMA versus TPA cations. However, using the iodide salts, differences in transport are amplified. In going through any sequence of cation of the same anion, the increase in transport for increasing $\mathrm{C} / \mathrm{N}^{+}$, is sigmoidal in nature indicating a criticality in this ratio to be able to implement sufficient hydrophobicity to move cations into the less polar domain. The higher tetraalkyl homologues, tetrabutlyammonium (TBA) and tetrapentylammonium (TPenA), showed greatly enhanced transport. From these results, it is clear that the use of the iodide salts in the partitioning experiments is a way to discriminate what may be happening with SDA cations with regards to hydrophobic solvation.

Figure 2 shows the data for the analyses of compounds 1-20 by the transport measurement. These molecules, with few exceptions contain no other polar heteroatoms besides one or two $\mathrm{N}^{+}$. Surprisingly, the percentage of transport for these iodide salts conforms to the curve obtained from the simpler tetraalkylammonium iodides. This result implies that the shape of the curve in Fig. 1 is universal for these SDA's and that the C/N value determines the partitioning regardless of molecular geometry. An approximate percentage of transfer is large, being greater than $80 \%$ for $\mathrm{C} / \mathrm{N}^{+}>16$, and then decreases to almost zero as the ratio drops below 10. Interestingly, this also defines the window where most of the SDA's leading to new molecular sieve structures have been found. It is as though a moderate amount of hydrophobicity may be desirable to enhance the effectiveness of the SDA. 
Recently, Burkett and Davis [24-26] have come to the conclusion that intermediate hydrophobicity of the SDA is necessary for structure-direction to occur. By observing whether TMA, TEA, TPA, TBA and TPentA: (i) orders silica (by ${ }^{1} \mathrm{H}^{2}{ }^{29} \mathrm{Si} \mathrm{CP} \mathrm{MAS}$ NMR) in reaction mixtures appropriate for zeolite synthesis and (ii) forms a zeolite at a temperarure of $110{ }^{\circ} \mathrm{C}$, Burkett and Davis claimed that intermediate hydrophobicity of the SDA is required for organic-silicate interactions since only TPA ordered silicate species and gave a zeolite product at $110^{\circ} \mathrm{C}$. The proposed mechanism of assembly involved inorganic-organic composite species whose formation is initiated by overlap of hydrophobic hydration spheres of both the organic and inorganic components with subsequent release of ordered water to establish favorable intermolecular van der Waals interactions [26]. (The release of ordered water certainly can provide one of the thermodynamic driving forces for the assembly process [21].) Burkett and Davis suggested that TMA and TEA must not be sufficiently hydrophobic to elicit interactions with hydrophobically hydrated silicates while TBA and TPentA most likely phase separate into aggregates at $110^{\circ} \mathrm{C}$ [26]. The partitioning results shown here also suggest the need for intermediate hydrophobicity in the SDA.

The other aspect of the SDA uniqueness we chose to focus on was the geometry which was considered in terms of size and rigidity. The extent of tertiary and quaternary connectivities in the skeleton (see Scheme III) can be a measure of rigidity (this can be contrasted with conformational flexibility). For example, if all of the carbon atoms are no greater than secondary, then there is a chain; this provides optimum flexibility. Table 1 shows the number of tertiary and quaternary connectivities for each of the 20 SDA's used in the transport studies and the high-silica molecular sieves formed by using conditions where $\mathrm{SiO}_{2} / \mathrm{B}_{2} \mathrm{O}_{3}$ or $\mathrm{SiO}_{2} / \mathrm{Al}_{2} \mathrm{O}_{3}$ might range from 30-100.

There are approximately three types of SDA used in this study. Compounds of the first type are rigid, bulky and relatively short $(<10 \AA$ for the longest axis) in terms of their geometry. This group has the most restricted conformation, and can result in the 
crystallization of unique molecular sieves. The sizes of these SDA's vary slightly from one another but their fit in a specific molecular sieve pore is idealy tight and allow even longrange stacking sequences for layers of the growing crystal to be controlled towards a single polymorph. For example, the use of $\mathbf{5 a}, \mathbf{5 b}$ or $\mathbf{9}$ all yield CIT-1 which is a pure, single polymorph of the borosilicate sieve, SSZ-33 [10]. In terms of hydrophobicity, this first group of rigid SDA all have $\mathrm{C} / \mathrm{N}^{+}$in the range of $12-13$. These molecules have been useful in the synthesis of new molecular sieve structures and compositions (see Table 1) and in particular favor the formation of 12-ring molecular sieves. This trend once again suggests that rigid molecules with moderate hydrophobicity (10-50\% transport in the partition experiment) may be the best SDA choices in searching for new high-silica, 12-ring molecular sieves. In our study, SDA molecules 5, 9, 10, 11, 13-19 fall into this grouping.

Compounds of the second type are characterized as long and flexible, and more loosely fit 12-ring pores. SDA's $\mathbf{3}$ and $\mathbf{7}$ are in this group. $\mathbf{3}$ is reported to be a strong SDA for BEA $[9,31]$ and considered to be an ideal building block itself for the design of subsequent SDA's that may control the stacking disorders in the growth of pure polymorphs of BEA [44]. The $\mathrm{C} / \mathrm{N}^{+}$value for 3 is 16 and transport of the iodide salt to chloroform is quite high, $80 \%$. However, the newer SDA derivative 7 containing a second charged nitrogen, hardly transfers into chloroform. The geometry of the two molecules is expected to be almost the same. The use of each molecule gave MTW. Using 7 we might expect to crystallize a product with higher lattice substitution, introducing the more hydrophilic centers from $\mathrm{Al}$ or $\mathrm{B}$ incorporation. Indeed, using 7 we are able to crystallize a more substituted MTW structure than can be obtained with 3. MTW using 7 has a $\mathrm{Si} / \mathrm{B}=40$ while $\mathrm{MTW}$ using 3 gives $\mathrm{Si} / \mathrm{B}>230$. If an increase in boron gel content is made for the synthesis with 3 , BEA becomes the crystallized product. A similar result had recently been reported by Zones for the use of the "exo" isomer of SDA 19 [45]. An 
interesting question that remains is whether the conformation of $\mathbf{3}$ changes in the two products (MTW and BEA).

Compounds of a third group were designed to control the stacking randomness in BEA crystallization which would lead to a single polymorph. Thus, SDA's 1, 2 and 6 are related to $\mathbf{3}$. However, they also contain rigid, bulky substructure related to $\mathbf{5}$ and $\mathbf{9}$. Moreover, this substructure possesses chirality having been derived from optically active myrtanyl amine. On the basis of the fact that 5 crystallized CIT-1, SDA's 1, 2 and $\mathbf{6}$ should fit into the 12-ring pore more tightly than 3 . The $\mathrm{C} / \mathrm{N}^{+}$values for these three SDA are 22, 19 and 10, respectively. From Fig.2, it is clear that the transport of $\mathbf{1}$ and $\mathbf{2}$ are high and that they may simply be too hydrophobic to produce a molecular sieve. To date, their use in molecular sieve syntheses has produced no crystalline product. While attempting to prepare molecular sieves in the presence of $\mathbf{1}$ or $\mathbf{2}$ under the usual hydrothermal conditions has proven difficult, it may be possible that if hydrophobic aggregates are an impediment to their use, they could be dissociated by conducting reactions at yet higher temperatures or by adding co-solvents such as alcohols.

The less hydrophobic 6 yielded MTW rather than BEA in synthesis studies. The MTW crystallization was incomplete and we suppose that the bulky myrtanyl group would be too large to fit into the MTW 12-ring ( this 12-ring is puckered and its effective crosssection is smaller than other 12-ring pores like those found in CIT-1 and AFI). Conversely, 6 can also be viewed as an analogue of 5 that crystallizes CIT-1. 6 effectively prevents CIT-1 crystallization. It may be the case that an explanation for both facets of using 6 is that the proximity of the two charged nitrogens renders 6 well-suited to base-driven elimination at zeolite reaction temperatures. Indeed, ${ }^{13} \mathrm{C}$ NMR of the corresponding $\mathrm{MTW}$ revealed that 6 was no longer intact. If this is the case, then there may be a sufficient rate of MTW crystallization from the piperidine fragment before the net hydroxide level drops too low (from consumption in the elimination reaction ) in order to promote any further zeolite crystallization. There are two additional observations that support the case for 
Hofmann elimination by base-driven abstraction of $\beta$-positioned protons in the cismyrtanylammonium moiety. First, the SDA 7 that lacks the corresponding hydrogen did not decompose since the ${ }^{13} \mathrm{C}$ NMR of as-made MTW showed 7 remains intact. 7 can fit into 1D pore of MTW as a result of free rotation around the $N$-benzyl bond. Second, during the coupling reaction of tosylamide I and cis-myrtanyl tosylate (II) (see Scheme I), elimination of $\mathrm{TsOH}$ from tosylate II occurs easily, results in low yields ( $33 \%$, see experimental section) of the coupled product and is accompanied by the formation of $\beta$ pinene as a side product. Unlike $c i s$-myrtanyl tosylate, the trans-isomer does not suffer from such elimination because the $\beta$-positioned hydrogen of tosyloxy group is sterically hindered.

The remaining SDA's in our study constitute behavior that is not generalizable to other molecules. Compounds $\mathbf{4}$ and $\mathbf{1 2}$, which contain triethylammonium groups, gave no crystalline products. However, these organics likely degrade via Hofmann elimination reactions. It is known that in the synthesis of BEA from tetraethylammonium (TEA), a considerable pressure is formed during synthesis and arises from ethylene formation by the above-mentioned elimination reaction.

Diquat $\mathbf{8}$ is an exceptional example of a molecule with maximum conformational flexibility (although possessing a discrete length ) working as a specific SDA for a single unique zeolite in the more hydrophilic regime. Unlike other linear diquats $\left(\mathrm{C}_{7}, \mathrm{C}_{8}, \mathrm{C}_{11}\right.$, $\mathrm{C}_{12}$ ) which lead to the crystallization of MTT and ZSM-48 [33, 46], the use of 8 gives the NES zeolite [47] which consists of 10-ring straight channels interconnected by 12-ring cavities running between the 10-rings. However, as was recently pointed out by Nakagawa [48] it may be better to think of this SDA as a pairwise space-filler in crystallizing NES. This result suggests that even some flexible SDA's can work for the synthesis of new molecular sieves (for example at high-silica conditions in Table 1, 8 produces ZSM-48 just as would the other linear chain diquats). 
Recently, both Lobo and Davis [19] and Nakagawa [43] independently discovered that $N$-methylsparteinium (20) has a high synthesis selectivity for the AFI structure (12ring, one-dimensional). This tetracyclic ring system appears too large and too hydrophobic to work as a SDA. However, it may be that at synthesis temperature, a less favorable conformation is trapped by the building nuclei. Figure 3 illustrates how a molecule like 20 must be constrained to make a one-dimensional product like AFI while conversely the bent, rigid morphology of SDA 5 appears to provide a poor fit for AFI but is well-suited to be stabilized in the interconnected $12 / 10$ system of CIT-1.

\section{Conclusions}

Various new organic SDA's are designed and synthesized. The hydrophobicity of the organic SDA are found to be best evaluated when the SDA is an iodide salt by measuring the phase transfer behavior from water to chloroform. The geometry of the SDA's are evaluated by considering their tertiary and quaternary connectivities. These properties of the organic SDA's are correlated to their ability to produce high-silica molecular sieves. When the SDA has extremely hydrophobic character, crystallization of a molecular sieve is difficult. Introduction of an extra charge into a hydrophobic SDA gives it a more hydrophilic character that enables molecular sieve structure-direction. Rigid, bulky and relatively short $(<10 \AA$ for the longest axis) molecules with moderate hydrophobicity are the best candidates for the structure-direction of new high-silica molecular sieves. 


\section{Acknowledgments}

Financial support of this work has been provided by the Chevron Research and Technology Company. We are grateful to Dr. Yumi Nakagawa of the Chevron Research and Technology Company for synthesizing SDA's $\mathbf{1 0}$ and $\mathbf{1 4}$ and Christopher B. Dartt for preparing SDA 15. We also thank Shervin Khodabandeh for collecting the ${ }^{1} \mathrm{H}-{ }^{13} \mathrm{C} \mathrm{CP}$ MAS NMR spectra of as-made molecular sieve samples and Dr. Raul F. Lobo for helpful suggestions.

\section{References}

[1] E.M. Flanigen, R.L. Patton and S.T. Wilson, Stud. Sur. Sci. Catal., 37 (1988) 13.

[2] M.E. Davis and R.F. Lobo, Chem. Mater., 4 (1992) 756.

[3] M.E. Davis and S.I. Zones, in M.L. Occelli and H. Kessler (Eds.), Synthesis of Microporous Materials: Zeolites, Clays and Nanostructures, Marcel Dekker, New York, in press.

[4] J.C. Braun and G.S. Fisher, Tetrahedron Lett., 21 (1960) 9.

[5] H.C. Brown and G. Zweifel, J. Am. Chem. Soc., 81 (1959) 247.

[6] D.I. Weisblat, B. J. Magerlein and D. R. Myers, J. Am. Chem. Soc., 75 (1953) 3630.

[7] H.C. Brown, K-W. Kim, M. Srebnik and B. Singaram, Tetrahedron, 43 (1987) 4071.

[8] R. Shirai, K. Aoki, D. Sato, H-D. Kim, M. Murakata, T. Yasukata and K. Koga, Chem. Pharm. Bull., 42 (1994) 690.

[9] R.B. Calvert, C.D. Chang and E.W. Valyocsik, Eur. Pat., EP 164.208 (1985).

[10] R.F. Lobo and M.E. Davis, J. Am. Chem. Soc., 117 (1995) 3766.

[11] O. Mitsnobu, Synthesis, 1981, 1.

[12] C.F. Lane, Synthesis, 1975, 135. 
[13] Y. Nakagawa, U. S. Patent, 5,268,161 (1993).

[14] S.I. Zones, U. S. Patent, 4,665,110 (1987).

[15] R.D. Bach, J. Org. Chem., 33 (1968) 1647.

[16] G.E. McCasland and S. Proskow, J. Am. Chem. Soc., 78 (1956) 5646.

[17] Y. Nakagawa, U. S. Patent, 5,254,514 (1993).

[18] Y. Nakagawa, U. S. Patent, 5,281,407 (1994).

[19] S.I. Zones, M.M. Olmstead and D.S. Santilli, J. Am. Chem. Soc., 114 (1992) 4195.

[20] R.F. Lobo and M.E. Davis, Micropor. Mater., 3 (1994) 61.

[21] M.M. Helmkamp and M.E. Davis, Annu. Rev. Mater. Sci., 25 (1995) 761.

[22] I. Petrovic, A. Navrotsky, M.E. Davis, and S.I. Zones, Chem. Mater., 5 (1993) 1805 .

[23] A. Shimizu and Y. Taniguchi, Bull. Chem. Soc. Jpn., 63 (1990) 1572 and 3255.

[24] S.L. Burkett and M.E. Davis, J. Phys. Chem., 98 (1994) 4647.

[25] S.L. Burkett and M.E. Davis, Chem. Mater., 7 (1995) 920.

[26] S.L. Burkett and M.E. Davis, Chem. Mater., 7 (1995) 1453.

[27] Y.Y. Wen, The Structure of Water, Chapt. 16, 1961.

[28] S.I. Zones, Y. Nakagawa and J.W. Rosenthal, Zeoraito, 11 (1994) 81.

[29] H.Z. Sommer, H.I. Lipp and L.L. Jackson, J. Org. Chem., 36 (1971) 824.

[30] A. Thangaraj, P.R. Rajamohan, S. Ganapathy and P. Ratnasamy, Zeolites, 11 (1991) 69 and references cited therein.

[31] M.K. Rubin, Eur. Pat. Appl., 159845 (1985).

[32] R.F. Lobo, Ph. D. Thesis, Caltech, 1994.

[33] A. Moini, K.D. Schmitt, E.W. Valyocsik and R.F. Polomski, Zeolites, 14 (1994) 504.

[34] Y. Nakagawa, U. S. Patent, 5,317,753 (1994).

[35] S.I. Zones, L. T. Yuen, U.S.Patent, 5,187,132 (1993). 
[36] R.F. Lobo, S.I. Zones and M.E. Davis, J. Incl. Phenom., 21 (1995) 47.

[37] Y. Nakagawa, Stud. Sur. Sci. Catal., 84 (1994) 323.

[38] Y. Nakagawa, Pat. Appl., WO 95/09812 (1995).

[39] S.I. Zones, R.A. Van Nordstrand, D.S. Santilli, D.M. Wilson, L. Yuen and L.D. Scampavia, Stud. Sur. Sci. Catal., 49A (1989) 299.

[40] S.I. Zones, U. S. Patent, 4,826,667 (1989).

[41] S.I. Zones and Y. Nakagawa, Micropor. Mater. 2 (1994) 543.

[42] S.I. Zones, Y. Nakagawa and L.T. Yuen, to be submitted.

[43] Y. Nakagawa, U. S. Patent, 5,271,922 (1993).

[44] A.P. Stevens and P.A. Cox, J. Chem. Soc., Chem. Commun., 1995, 343.

[45] S.I. Zones, Micropor. Mater., 2 (1994) 281.

[46] A.C. Rohrman, Jr., R.B. LaPierre, J.L. Schlenker, J.D. Wood, E.W. Valyocsik, M.K. Rubin, J.B. Higgins and W.J. Rohrbaugh, Zeolites, 5 (1985) 352.

[47] M.D. Shannon, J.L. Casci, P.A. Cox and S.J. Andrews, Nature, 353 (1991) 417.

[48] Y. Nakagawa, Stud. Sur. Sci. Catal., 97 (1995) 53. 
Table 1. Properties of Structure-Directing Agents and Molecular Sieves Formed

\begin{tabular}{lllll} 
SDA & $3^{\circ}{ }^{a}$ & $4^{\circ}$ & $\mathrm{C}^{\mathrm{a}} \mathrm{N}^{+}$ & $\begin{array}{l}\text { Molecular Sieves } \\
\text { Formed }^{\mathrm{b}}\end{array}$ Ref. $^{\mathrm{d}}$ \\
\hline
\end{tabular}

1<smiles>CN(CC1CC2CCC1C2)CC(C)(C)Cc1ccccc1</smiles>

2<smiles>O=[N+](Cc1ccccc1)CC1CC2CCC1C2</smiles>

3<smiles>O=[N+]([O-])Cc1ccccc1</smiles>

2

4

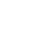<smiles>CCN(CC)CC1CC2CCC1C2</smiles>

$5 a$<smiles>[CH-]</smiles>

$5 b$<smiles>CN(C)CC1CC2CCC1C2</smiles>

6<smiles>CCCC(CC1CC2CCC1C2)CN(C)CC1CCCCC1</smiles>

7

3

3

5

3



2

22

19

Amorphous*

this work

16

$\mathrm{BEA}(\mathrm{Al}), \mathrm{EUO}(\mathrm{Al})^{\mathrm{e}}, 9,30,31$ $B E A(B) *$, this work MTW*, EUO*,f

1

13

16

Amorphous*

this work

1

10

$\operatorname{MTW}(B)^{*}$

this work

0

8.5
CIT-1(B)*, CIT-1(B) this work 
Table 1 (Continued)

\begin{tabular}{|c|c|c|c|c|c|c|}
\hline & SDA & $3^{\circ a}$ & $4^{\circ} \mathrm{a}$ & $\mathrm{C} / \mathrm{N}^{+}$ & $\begin{array}{l}\text { Molecular Sieves } \\
\text { Formed }^{\mathrm{b}}\end{array}$ & Ref. $^{d}$ \\
\hline 8 & $\mathrm{Me}_{3} \stackrel{+}{\mathrm{N}}-\left(\mathrm{CH}_{2}\right){ }_{10}-\stackrel{+}{\mathrm{N}} \mathrm{Me}_{3}$ & 0 & 0 & 8 & $\begin{array}{l}\text { NES(Al), } \\
\text { ZSM-48 }\end{array}$ & 33 \\
\hline 9 & & 3 & 1 & 13 & CIT-1(B)* & this work \\
\hline 10 & & 2 & 2 & 12 & $\begin{array}{l}\text { SSZ-35(Al), } \\
\text { SSZ-35(B), } \\
\text { SSZ-35 }\end{array}$ & 34 \\
\hline 11 & & 3 & 0 & 12 & $\begin{array}{l}\text { SSZ-13(Al), } \\
\text { SSZ-23(Al), } \\
\text { SSZ-23 }\end{array}$ & 35 \\
\hline 12 & & 1 & 0 & 12 & Amorphous & 28 \\
\hline 13 & & 2 & 1 & 12 & $\begin{array}{l}\text { SSZ-13(Al), } \\
\text { SSZ-31(B), } \\
\text { SSZ-31 }\end{array}$ & 36 \\
\hline 14 & & 5 & 0 & 12 & $\begin{array}{l}\text { SSZ-13(Al), } \\
\text { SSZ-33(B), } \\
\text { SSZ-37 }\end{array}$ & 37 \\
\hline
\end{tabular}


Table 1 (Continued)

\begin{tabular}{|c|c|c|c|c|c|c|}
\hline & SDA & $3^{\circ a}$ & $4^{\circ a}$ & $\mathrm{C} / \mathrm{N}^{+}$ & $\begin{array}{l}\text { Molecular Sieves } \\
\text { Formed }^{\text {b }}\end{array}$ & Ref. $^{d}$ \\
\hline 15 & & 3 & 0 & 11 & $\begin{array}{l}\operatorname{MEL}(A) \text {, } \\
\text { MEL(B), } \\
\text { MEL }\end{array}$ & 38 \\
\hline 16 & & 3 & 1 & 13 & $\begin{array}{l}\text { SSZ-13(Al), } \\
\text { SSZ-13(B), } \\
\text { AFI }\end{array}$ & 39 \\
\hline 17 & & 5 & 0 & 13 & $\begin{array}{l}\text { SSZ-25(Al), } \\
\text { SSZ-25(B), } \\
\text { AFI }\end{array}$ & 36,40 \\
\hline 18 & & 2 & 2 & 9 & $\begin{array}{l}\text { SSZ-26(Al), } \\
\text { SSZ-33(B) }\end{array}$ & 19,41 \\
\hline 19 & & 5 & 0 & 13 & $\begin{array}{l}\operatorname{MOR}(\mathrm{Al}), \\
\text { SSZ-33(B), } \\
\text { SSZ-31 }\end{array}$ & 42 \\
\hline 20 & & 5 & 1 & 16 & $\begin{array}{l}A F I(B) \\
A F I\end{array}$ & 19,43 \\
\hline
\end{tabular}


Table 1 (Continued)

a. Number of tertiary $\left(3^{\circ}\right)$ or quaternary $\left(4^{\circ}\right)$ carbons in molecule or nitrogen as part of a ring (see Scheme III).

b. Letters in brackets denote whether Al or B was used. If no bracket is provided, then only pure-silica was used in the synthesis.

c. * denotes the use of boron beta in the synthesis mixture.

d. Gel composition and temperature in this work are as follows unless otherwise noted. $\mathrm{SiO}_{2} / \mathrm{M}_{2} \mathrm{O}_{3}=20-\infty$ (M=B or $\mathrm{Al}$ ), $\mathrm{OH}^{-} / \mathrm{SiO}_{2}=0.3, \mathrm{H}_{2} \mathrm{O} / \mathrm{SiO}_{2}=50-65, \mathrm{R} / \mathrm{SiO}_{2}=0.1-0.2, \mathrm{Na}^{+} / \mathrm{SiO}_{2}=0.1,135-175^{\circ} \mathrm{C}$.

e. $\mathrm{SiO}_{2} / \mathrm{Al}_{2} \mathrm{O}_{3}=300, \mathrm{OH}^{-} / \mathrm{SiO}_{2}=0.11, \mathrm{H}_{2} \mathrm{O} / \mathrm{SiO}_{2}=11, \mathrm{R} / \mathrm{SiO}_{2}=0.09, \mathrm{Na}^{+} / \mathrm{SiO}_{2}=0.12,100-150{ }^{\circ} \mathrm{C}$.

f. $\mathrm{OH}^{-} / \mathrm{SiO}_{2}=0.5, \mathrm{H}_{2} \mathrm{O} / \mathrm{SiO}_{2}=23, \mathrm{R} / \mathrm{SiO}_{2}=0.5, \mathrm{Na}^{+} / \mathrm{SiO}_{2}=0,140^{\circ} \mathrm{C}$. 


\section{Figure Captions}

Fig.1. Transport of simple tetraalkylammonium iodides, bromides, and hydroxides from water to chloroform.

Fig.2. Transport of simple tetraalkylammonium iodides and synthesized structure-directing agents (SDA's) from water to chloroform. Refer to Table 1 for SDA structures.

Fig.3. Contrast of methylsparteinium 20, a long cylindrical molecule, with $\mathbf{5 a}$, a bent, rigid quaternary ammonium compound. The former can stabilize 1-dimentional 12-rings like AFI, but not form the $12 / 10$ system (same 12-ring net) CIT-1. 

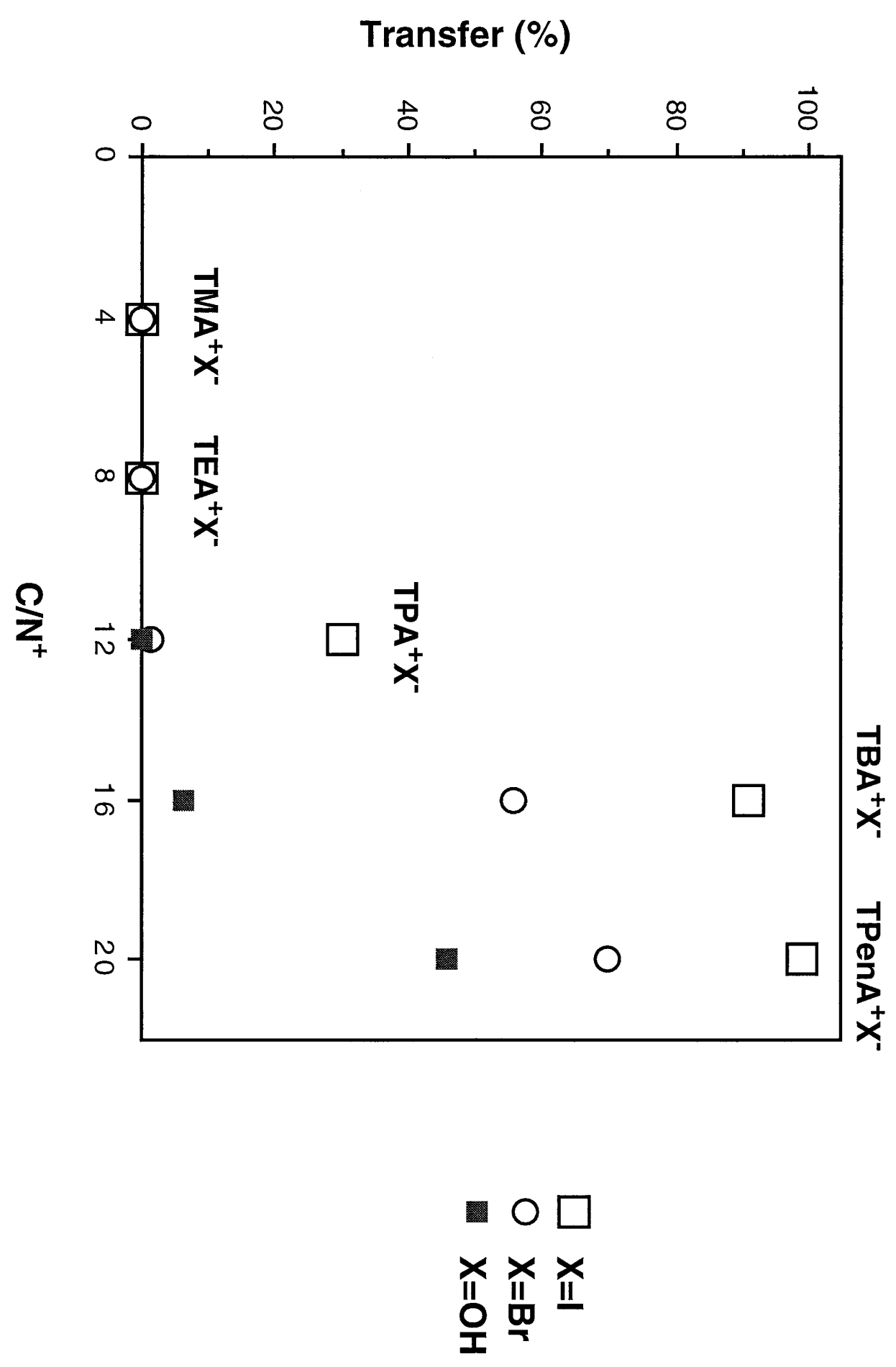

$\stackrel{\frac{\pi}{0}}{\frac{1}{1}}$ 


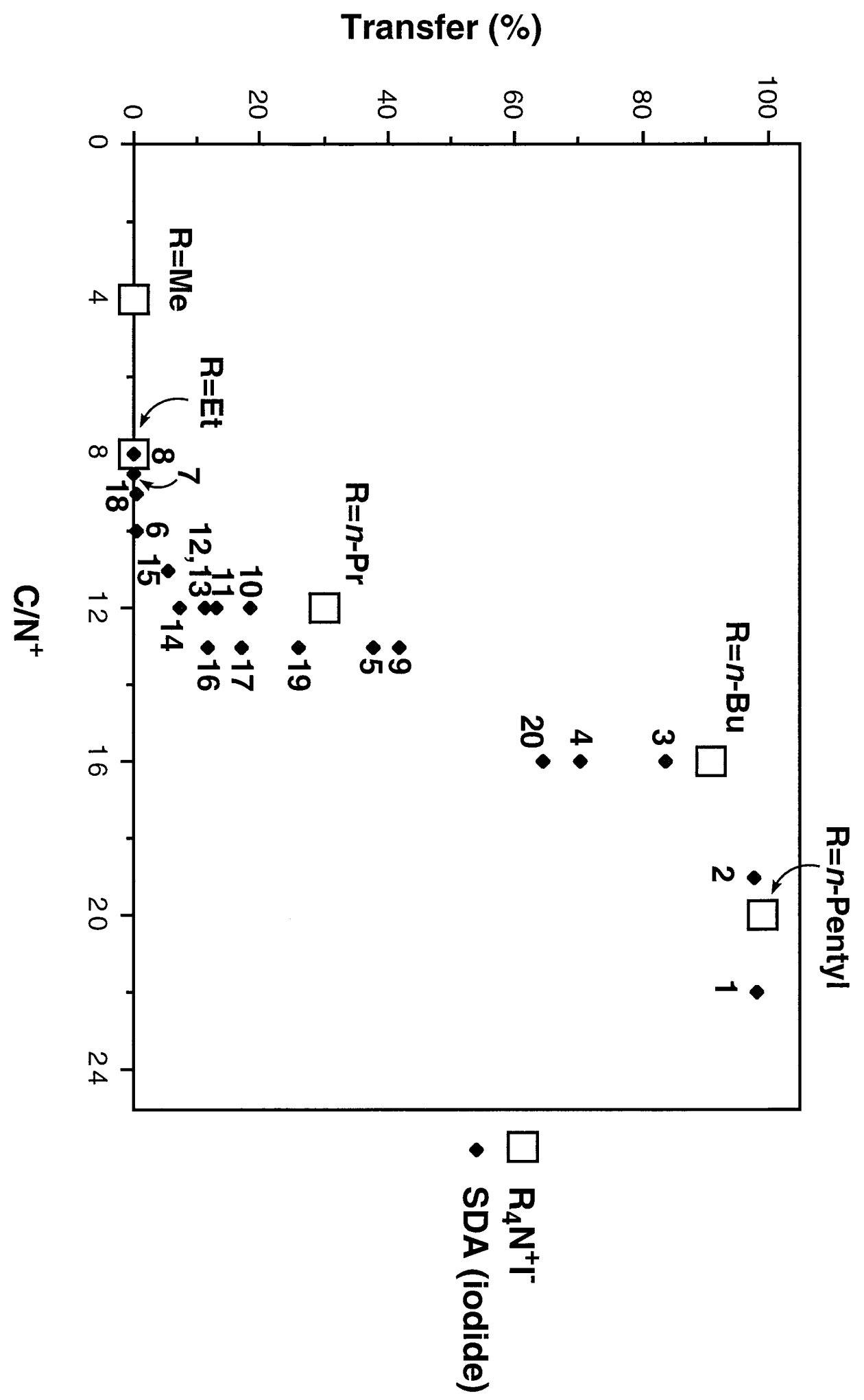




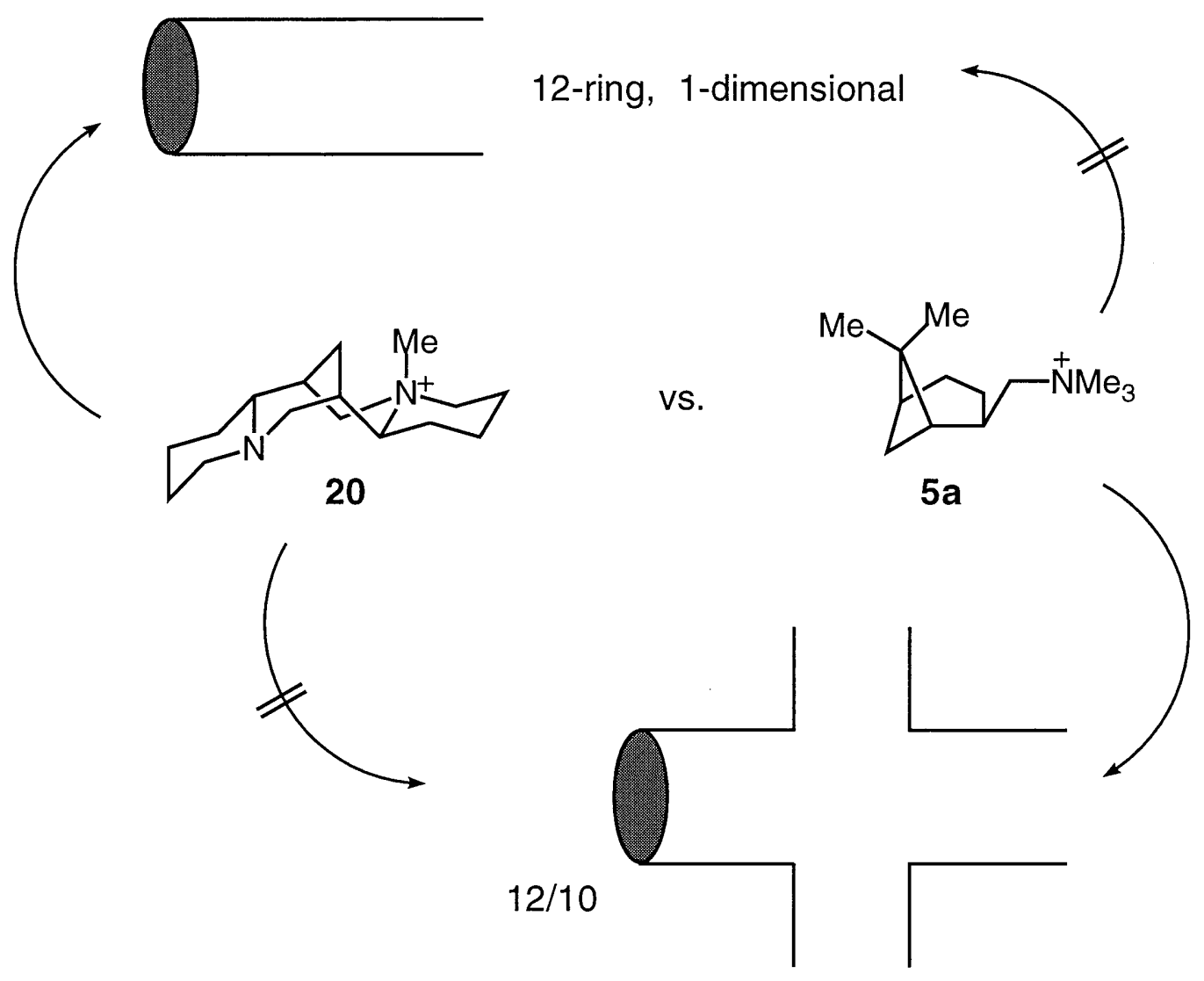

Figure 3 
Scheme I
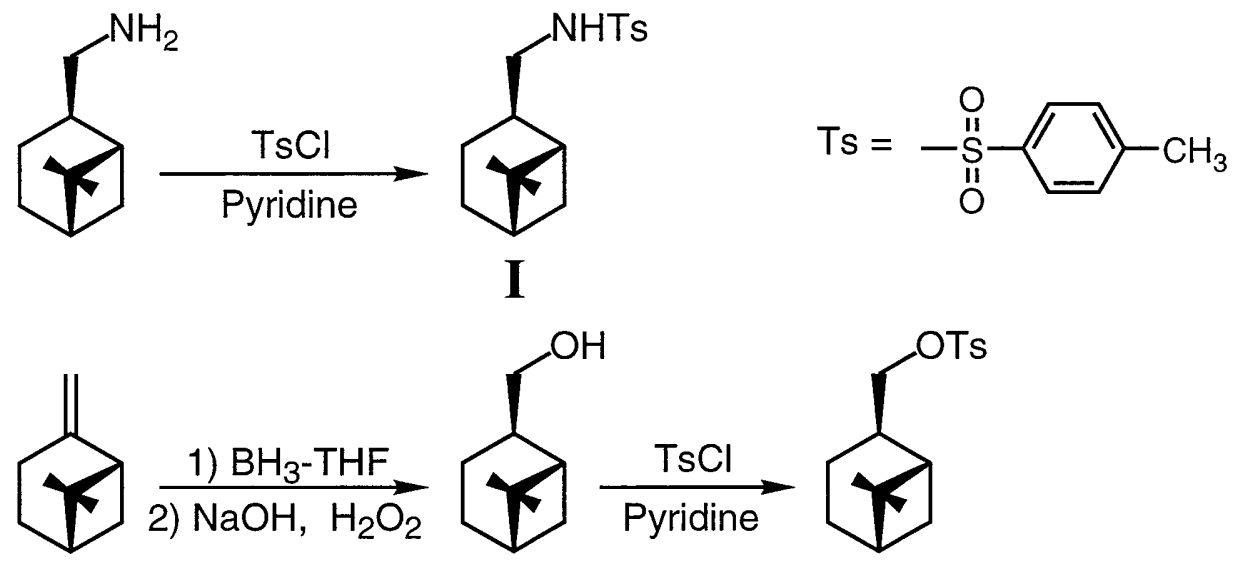

(-)- $\beta$-Pinene

II

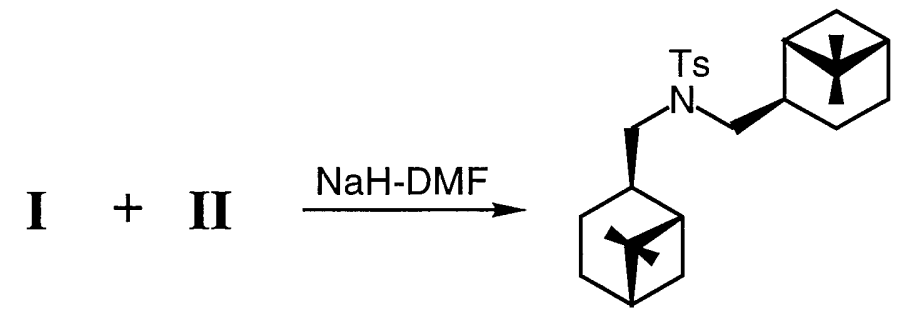<smiles>COC(C)(C(C)(C)O)C(C)(C)O</smiles><smiles>O=C(O)C(Br)(Br)Br</smiles>

1

Representative sequence of steps used to couple structural components and synthesize SDA 1. 


\section{Scheme II}

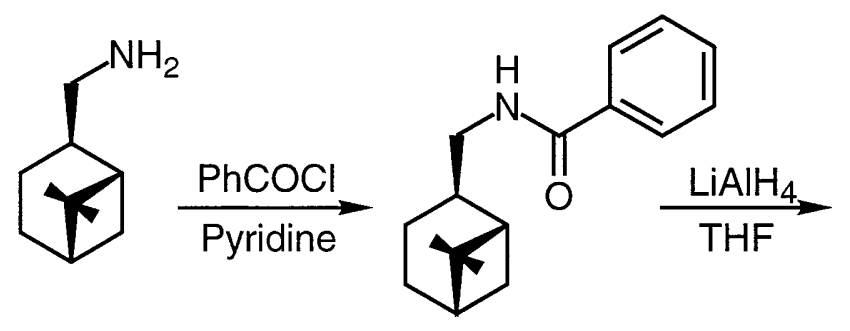

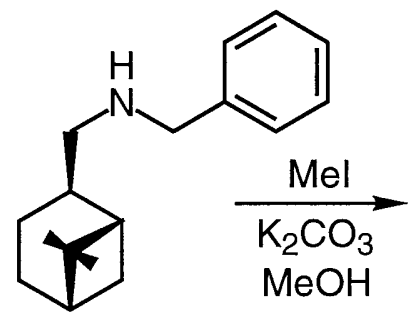<smiles>CN(Cc1ccccc1)C[C@@H]1CC[C@H]2C[C@H]1C2</smiles>

Representative sequence of steps used to couple structural components and synthesize SDA 2. Many of these same steps are involved in the synthesis of SDA molecules 3-19. 


\section{Scheme III}<smiles>[Y]CCC([R])([R])[R7]</smiles><smiles>[R]C([R])([R])CC[Se]C</smiles><smiles>Cc1ccccc1CCCC[Se]</smiles>
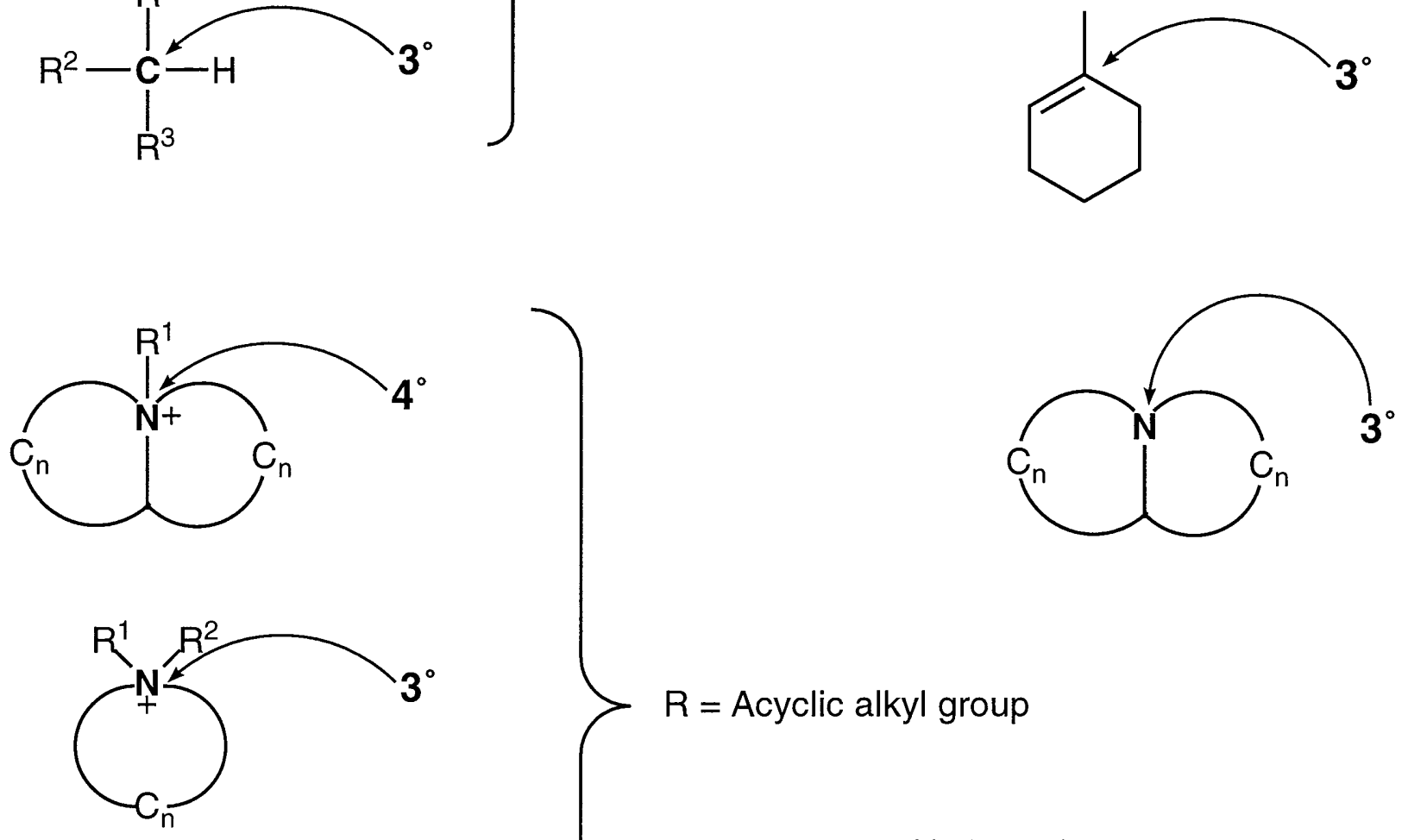

$R=$ Acyclic alkyl group

$$
-\mathrm{C}_{\mathrm{n}}-=\text { Hydrocarbon chain }
$$

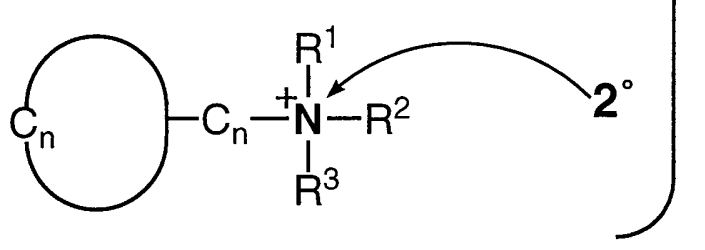

Definition of connectivity of carbons and nitrogens in this work.

We define the connectivity of saturated aliphatic carbons as usual.

We consider aromatic quaternary carbons and olefinic quaternary carbons included in rings as $3^{\circ}$ because the rigidity of unsaturated rings is similar to that of their saturated form.

When more than one $R^{\prime}$ s are attached to a nitrogen, we consider $R^{2}$ and $R^{3}$ as $H$ in order to discriminate the rigidity around different kind of quaternary nitrogens. Therefore, only nitrogen that is a part of rings can be $3^{\circ}$ or $4^{\circ}$. 